\title{
A RARE CASE OF ADENOID CYSTIC CARCINOMA OF ETHMOID SINUS
}

\author{
C. Bharath, Indudhara. P. B.
}

1. Professor \& HOD, Department of Pathology, Vijayanagara Institute of Medical Sciences, Bellary.

2. Post Graduate Student, Department of Pathology, Vijayanagara Institute of Medical Sciences, Bellary.

\section{CORRESPONDING AUTHOR}

Dr. C. Bharath,

Professor and HOD,

Dept. of Pathology,

Vijayanagara institute of Medical Sciences, Bellary

E-mail: bhar5anu@yahoo.co.in,

Ph: 00919483980702.

ABSTRACT: Adenoid cystic carcinoma is more common in minor salivary glands, uncommon in parotid gland and rare in paranasal sinuses. These are more aggressive and fatal. Such tumors of the accessory nasal sinuses causing proptosis have been reported so rarely in ophthalmic literature. An adult aged 31 years presented with proptosis of right eye, nasal obstruction and bleeding from right nose. CT scan showed soft tissue attenuation mass with destruction of bony structures and extension to right orbit. Biopsy was done through trans nasal route. A histological diagnosis of Adenoid cystic carcinoma of ethmoid sinus was made.

KEY WORDS: Paranasal sinus, Adenoid cystic carcinoma, ethmoid sinus.

INTRODUCTION: Adenoid cystic carcinoma is a rare tumor that accounts for less than $1 \%$ of all head and neck malignancies and $10 \%$ of all salivary glands. They have propensity to spread to contiguous intracranial structures like sellar and parasellar areas. Long disease free interval has been observed in most cases following radical surgery and radiotherapy ${ }^{1}$.

It is a slowly progressive and relentless tumor that has a tendency to recur locally and metastasize distantly. They commonly present with mass/epistaxis.

Because of its rarity in ethmoid sinus, this case is presented with review of literature.

CASE REPORT : A 31 year old male, presented to ENT OPD with mass in right nostril, bleeding and proptosis of right eye with facial asymmetry. Patient had epistaxis from right nose intermittently since 3 years, followed by nasal obstruction since 2 years and noticed mass since 8 months with proptosis of right eye and facial asymmetry since 6 months not associated with blurring of vision. On examination, anterior rhinoscopy showed solitary mass grayish in color which bleeds on touch, totally obstructing the right nasal cavity with deviation of nasal septum to left. Paraxial proptosis of right eye seen only. Ear and throat was normal. Routine hematology, biochemical and urine examination is within normal limits. CT scan showed complete opacification of right ethmoid sinus and nasal cavity heterogenous echogenic soft tissue attenuation mass with destruction of bony structure. A biopsy was done from the nasal mass through Transnasal route and sent for HPE.

PATHOLOGICAL EXAMINATION: Grossly, multiple grey-white to grey-brown bits of tissue amounting to $1 \mathrm{cc}$ was received. On microscopy, multiple sections shows moderately pleomorphic epithelial cells arranged in groups, having small cystic spaces containing eosinophilic material (Fig.1) The tumor cells had small vesicular nuclei with indistinct nucleoli 
and scanty pink cytoplasm (Fig.2). Areas of tumor necrosis and surface ulceration are seen and diagnosed as Adenoid cystic carcinoma of ethmoid sinus.

DISCUSSION: Adenoid cystic carcinoma is rare in ethmoid sinus; however the distribution is as follows- antrum- $60 \%$, nasal cavity-30\%, nasopharynx- $2 \%$ and ethmoids $-3 \%{ }^{2}$. On review of literature, Billroth in 1859 first used the term 'cylindroma' to describe the histologic appearance of this tumor. In 1930s, Spies was the first to name the tumor as Adenoid cystic carcinoma and to identify the malignant nature of this disease. However in 1962, Tauxe, et al, described it as a cancer that pursues its course relentlessly and maliciously3. In 1974, Dr.John Connelly and Dr.Digman, published an article in Archives of Otolaryngology, describing adenoid cystic carcinoma as one of the most biologically destructive and unpredictable tumor of head \& neck which remains extremely difficult to treat till today.

Sinonasal malignancies (SNM) are rare. They are more common in Asia and Africa than in the United States, where about 2000 Americans develop these malignancies each year.

ACC can occur over a wide range with predominance from $4^{\text {th }}$ to $7^{\text {th }}$ decades with male preponderance. (Silverberg/section 6) These tumors have propensity to spread along the perineural spaces and recurrences often occur at distant sites along the course of the nerves supplying the primary area 5 .

ACC produces three architectural patterns, tubular (low grade) has best prognosis, cribriform (intermediate grade) and solid pattern having poor prognosis. Our case showed cribriform pattern of arrangement of tumor cells indicating intermediate prognosis. In literature it was noticed that ACC of head \& neck, originating in paranasal sinuses or nasal cavity have the poorest prognosis 6 . Prognostic factors include the location, tumor size, perineural growth, histological appearance and presence of tumor at the surgical margin. Therapeutic options include local or radical excision and radiotherapy.

If the tumors are found within the nerve at foramen rotundum, it is best controlled with radioactive implants and Iodine 125 seeds with long half-life are a promising source for this type of tumors ${ }^{7}$. Radiology plays an important role in defining regional extension and detecting perineural spread, local recurrences and distant metastases.

CONCLUSION: ACC is a rare tumor occurring in ethmoid sinus, it is locally aggressive with high rate of late recurrence due to perineural invasion to distant sites, after local excision. Thus histological evaluation for type of tumor is important for prognostic value and also it should be considered as one of the differential diagnosis for mass in nose.

\section{REFERENCES}

1. Wiseman SM, Popat SR, Rigual NR, Hicks WL, J Osner JB, Wein RO, et al: Adenoid cystic carcinoma of the paranasal sinuses or nasal cavity. A 40 year review of 35 cases. Ear nose throat Jr. 2002: 81: 510-514.

2. Spiro RH, Huvos AG: Stage means more than grade in adenoid cystic carcinoma. American journal of Surgery.1992: 164: 623-628.

3. Tauxe WN, McDonald JR, Devine KD: A century of cylindromas.ArchOtolaryngol. 1962: 78: 94-106.

4. Margaret Brandwein, Gensier: Sininasal and nasopharyngeal surgical pathology,Silverberg's Principle \& Practice of Surgical Pathology \& Cytopathology, 
Editors-Steven G Silverberg, Ronald A Delellis, Williams J Frable, 4th edition, Vol I, Elsevier: 2006, pages 794-95.

5. V.Palaindra, P NagarjunaRao\& G Ashok kumar: Adenoid cystic carcinoma of nasal cavity. A case report. Indian journal of Otolaryngology and head \& neck surgery. 2003: 55: 4345.

6. Cleveland D, Abrams AM, Melrose RJ, Handlers J. Solid adenoid cystic carcinoma of maxilla. Oral Surg Oral Med Oral Pathol. 1990: 69: 470-78.

7. Russell JD, Bleach NR, Glaser MG \&Cheeseman AD: Brachytherapy for recurrent nasopharyngeal and naso-ethmoid tumors. Journal of Laryngology and Otology. 1993: 107: $115-120$.

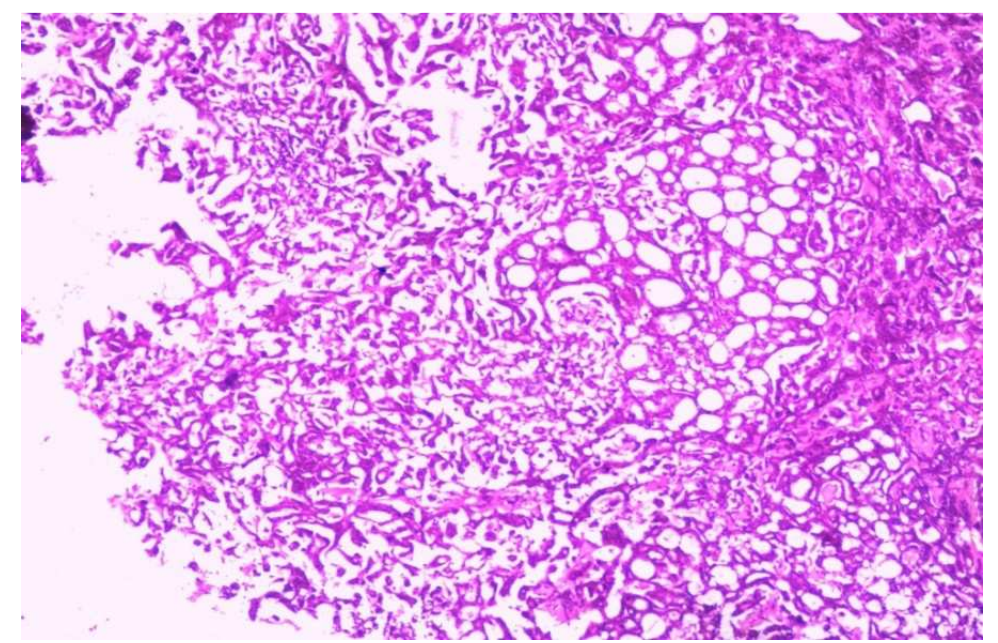

Fig.1. Histology, showing cribriform pattern of tumor cells. (H \& E 10 x)

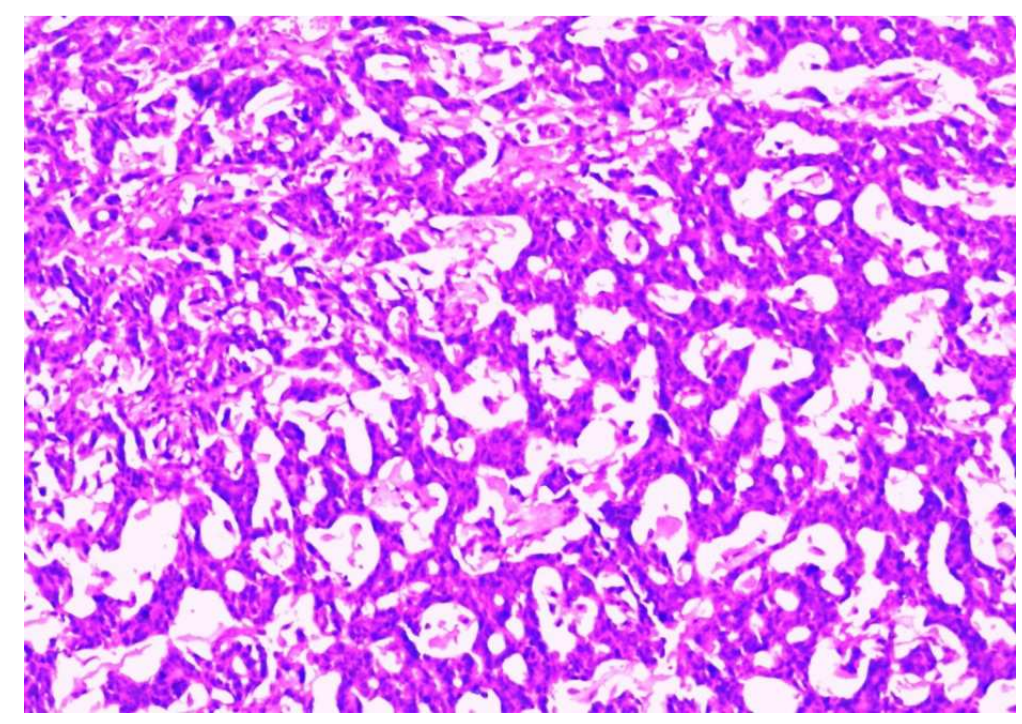

Fig.2. Higher magnification of above showing cystic spaces with eosinophilic material in the center of cystic spaces, cribriform pattern. (H \& E 100x) 